\title{
Natural gas and climate finance
}

\section{Introduction}

Fuel switching projects, particularly switching from coal to natural gas, have been heralded as a means to achieve rapid emission reductions worldwide (Ridley, 2011). Examples from countries such as Indonesia also suggest that gas resources can reduce energy poverty at the national level (Andadari, Mulder et al. 2014). As of September 2015, 425 projects have received Certified Emissions Reductions from the Clean Development Mechanism, for activities involving fuel switching to natural gas, capture of gas that would be otherwise flared or vented and prevention of pipeline leakages. Given all this, should international climate finance be used to fund natural gas projects?

Multilateral organisations such as the Regional Development Banks and the World Bank have generally favoured the inclusion of gas as a cleaner fuel in development strategies. Although there are dissenting voices inside these organizations, they often prioritise reducing carbon intensity over reducing the consumption of fossil fuels. The International Development Finance Club, for example, has advocated the inclusion of energy-efficiency projects in existing thermal power plants or the retro-fit of less intensive fuels as part of the Green Climate Fund thematic project categories (IDFC 2014). Japan is an extreme example, because its government (which is also one of the main donors to the GCF) advocates energy efficiency measures that involve fossil fuel projects with gas and coal. More moderate positions are defended by Europe-based donors. For example, the German KfW Bankengruppe (one of the first agencies accredited by the GCF) strongly supports a position that assumes that the performance of gas is unquestionable and the political case for gas can be argued convincingly. In Norway political sensitivities have generated a strong debate that may lead to a blanket ban on ODA for fossil fuels.

These positions contrast with those of civil society organisations and international NGOs which consider unacceptable the use of climate finance for any project that requires fossil fuels, including gas. When in March 2015 the Green Climate Fund partners refused to pass a blanket ban on fossil fuels, Karen Orenstein, a campaigner of Friends of the Earth US, famously said that the meeting felt like "a torture convention that doesn't forbid torture" (Goldenberg 2015). For campaigners such as Friends of the Earth, Greenpeace or Action Aid 
both the techno-economic and political case is against funding natural gas projects with climate finance. For international development organisations and development NGOs with experience on the ground, the case for gas is one that relies on the political imperative to facilitate energy access in less developed countries, rather than on the putative mitigation benefits that natural gas projects may have.

This paper provides a synthesis of arguments about whether natural gas projects should be integrated in the climate finance portfolios of ODA. The paper focuses in one of the largest climate finance commitments made by a single country, the UK's International Climate Fund (ICF). This synthesis builds upon the evidence from four sources: 1) a critical review of the literature on gas, climate finance and international development; 2) two seminar discussions with representatives of the UK Department for International Development (DFID) and the Department of Energy and Climate Change (DECC) who also provided feedback on a preliminary version of this paper; 3 ) insights from ten semi-structured interviews with representatives of organisations invested in this debate from the public sector, development banks and international NGOs; and 4) a comparative analysis of three case studies. The case studies were selected because interviewees mentioned them as rare examples that illuminate areas of controversy.

The evidence in this paper suggests that gas-related projects should be outside the remit of the ICF, and more generally, outside climate finance. However, there are some exceptions in which gas-related projects could be within the remit of the ICF, particularly when gas is used to facilitate energy access or when gas use follows the recovery of gas that would otherwise vented or flared, beyond the duty of care of the industry responsible for emissions. Some technical assistance programmes that consider gas alongside a wide portfolio of options may also fall within the ICF. In conclusion, this paper suggests that the evidence against using climate finance to fund gas-related projects is very strong, and that they should only be considered in exceptional circumstances.

\section{The UK's International Climate Fund}

The ICF is the UK's largest instrument to invest in climate finance. As of December 2015, the ICF is currently endowed with $f 3.87 \mathrm{bn}$ up to March 16 . Further $£ 5.8$ billion have been pledged for the period between April 2016 and March 2021. The funds come from DFID (62\%), DECC (34\%) and Defra (4\%). The spending review in November 2015 suggests that 
the funding for climate change and development projects is likely to increase in the coming years. The ICF enables activities that demonstrate low carbon, climate resilient growth, support international climate change negotiations and promote sustainable development. These include evidence-building activities; specific low carbon and climate resilient programmes; capacity building; and activities to mainstream climate change into UK development aid. To achieve this, the ICF supports both multi-lateral and bilateral bodies (Yeo 2015). About $57 \%$ of the ICF funds have contributed to multi-lateral instruments emerging from international negotiations such as the Global Environment Facility or the Climate Investment Funds. A significant part of these funds include the UK's pledges to the Green Climate Fund that were agreed in the 2009 Copenhagen Accord.

The rest of the ICF supports bilateral projects over which the UK has a greater degree of control. In bilateral projects, the UK Government has the capacity to work directly with countries and support their in-country needs; or it may create international projects to explore cross-cutting issues. Among other projects, for example, the ICF has invested $£ 24$ million in the programme GET FIT, which supports small scale renewable energy projects in Uganda, and $\mathrm{f} 36$ million in a project on Carbon Finance Markets for Africa.

The UK has invested Overseas Development Assistance (ODA) in fossil fuel projects for electricity generation and infrastructure development. In 2013 the UK announced that it would stop any international development funding for coal-related projects, such as coalfired stations. ${ }^{1}$ Two years later, a similar question emerges about whether a blanket ban on ODA should be applied to natural gas, or, at least, whether gas-related projects should be excluded from the remit of the ICF. While it is not difficult to find good examples of projects that should be funded with the ICF, establishing criteria for exclusions may be more complicated. Following the objectives stated in the ICF implementation plan and discussions with representatives of DFID and DECC, the following ICF criteria are relevant to examine gas-related projects:

- the impact on poverty alleviation;

- the contribution to GHGs emissions reductions;

\footnotetext{
${ }^{1}$ Written Ministerial Statement by Edward Davey on the UK's position on the public financing of coal plants overseas: https://www.gov.uk/government/speeches/uk-position-on-public-financing-of-coal-plants-overseas
} 
- the contribution to transformational impacts towards climate sustainability²;

- the additionality over business as usual, or over commercially fundable projects and whether the projects are cost-effective.

\section{Mitigation potential of fuel switching for electricity generation}

Enthusiasm for natural gas as a possible lower carbon energy generation fuel is most often sustained on a comparison with coal. For example, a report from the Breakthrough Institute, which called natural gas 'the Coal Killer', explained how natural gas is already displacing coal for energy generation in the US (Trembath, Luke et al. 2013). This transition, motivated by economic, rather than environmental, factors, is thought to be already reducing the GHGs emissions of the US (Lafrancois 2012).

More coal-fired and natural gas-fired power plants were built in the past decade than in any other previous decade and they will have a lifetime of around 40 years (Davis and Socolow 2014). Combined-cycle plants achieve greater efficiency with the combination of two cycles, one using the gas directly and a secondary one using the hot exhaust gases to turn another turbine (Busch and Gimon 2014). Natural-gas based generation looks better than coal, as efficiencies range from $38 \%$ to $45 \%$ in the most advanced plants (Larson, Li et al. 2012). In principle, the unit costs of electricity generation is lower in natural gas plants, although most calculations are restricted to locations where data is available, such as the US and Europe (Schumacher and Sands 2006, Larson, Li et al. 2012).

The GHGs mitigation benefits of natural gas depend on controlling the rate of leakages of methane associated to the extraction, transport and combustion of this fuel. Leakages are related both to intentional venting and unintentional release of methane because of equipment deficiencies or malfunctions. Most research models assume that substituting gas for coal is an effective means to reduce GHGs emissions only if leakage rates for new methane can be kept below $2 \%$ (Wigley 2011). While there is evidence that this threshold can be kept with current technologies, there is also considerable variation in the estimates of leakage rates of current natural gas exploitations. In the US, Trembath et al (2013)

\footnotetext{
${ }^{2}$ The ICF is in a relatively early stage in terms of evaluating the transformative potential of current projects. Nevertheless, transformative for the purposes of this paper relates to the possibility of a radical reconfiguration of the energy system, for example, through the large scale spread of renewables or through learning about new business models for sustainable energy.
} 
suggest that most estimates fall between 1 and 7\% and Brandt et al (2014) narrow the gap in the $2-4 \%$ range. The variation of estimates reflects the heterogeneity of conditions in which natural gas is exploited, even in a single country. Thus, the extent to which gas can work as a low carbon substitute for coal will depend on the infrastructure and technological conditions in which it is extracted, transported and used. The comparison between gas and coal also depends on the timeframe used to calculate future scenarios at country level. Generally, natural gas generation scenarios seem to lead to fewer emissions in the long term, with timeframes of over 100 years (Busch and Gimon 2014). The longer the time frame considered, the more likely that the emissions associated with gas-fuelled generation will be less than those associated with coal-fuelled generation. However, some studies have argued that, in shorter timeframes (e.g. 20 years) the substitution of coal with natural gas leads to a reduction of $\mathrm{SO}_{2}$ emissions and possible increases in $\mathrm{CH}_{4}$ emissions (Hayhoe, Kheshgi et al. 2002).

Taking a life cycle approach to natural gas generation requires considering the actual generation in relation to the extraction and transportation processes that make it possible. In Europe, for example, the need to transport natural gas vast distances across Siberia and Eastern Europe may lead to further leakages and hence, increase the emissions associated with natural gas generation over its whole life (Stanek and Bialecki 2014). The Wuppertal Institute estimated that long distance transportation of natural gas from Russia is linked to approximately $0.6 \%$ of the emissions of the gas delivered (Lechtenboehmer, Dienst et al. 2007). Even the most optimistic assessments of natural gas emphasise the need for appropriate regulation over the whole cycle (Makholm 2015). Thus, the comparison between gas and other fossil fuels depends on where the gas comes from and how. Moreover, future GHG emissions do not depend as much from existing infrastructures as from future ones, because the largest fraction of GHGs emissions will correspond to infrastructures that are yet to be built (Davis, Caldeira et al. 2010). One of the most powerful arguments for natural gas is that, as a transition fuel, it enables matching infrastructures and perceived needs to the actual possibilities provided by renewables. For example, renewables such as wind and solar are not easily integrated in conventional networks because weather fluctuations and lack of storage may lead to significant space and price variations. In this context, future projections of energy scenarios include 
'dispatchable fuels', which can provide balancing services (Haller, Ludig et al. 2012). This role can be played by hydropower and biomass when available, but these technologies are not without impact. Natural gas advocates argue that natural gas has lower capital costs than other fossil fuels and thus, it is less prone to technological lock in (Trembath, Luke et al. 2013). Natural gas is presented as the most adaptable dispatchable fuel because it is quicker to build and fire up. In this way, natural gas is thought of as 'bridge fuel' or as a 'partner' for renewable technologies (IGU 2015). However, lock-in gas pipelines for gas transport to the generation plants is equally worrying (Liang, Ryvak et al. 2012). Moreover, lock-in does not only relate to the construction of infrastructures, but also, to how an energy source is integrated in modern societies and economies, the kind of uses that it facilitates, the business models that favour one fuel over other, and the politics around gas.

Models suggest that the impact of methane leakages can be discounted when considering using natural gas during a transition period (Levi 2013). However, other models suggest that without policies that promote renewables and discourage the use of fossil fuels (including gas), abundant natural gas may actually delay the adoption of renewables (Shearer, Bistline et al. 2014). This may be particularly noticeable in an urban context in which gas-based generation may displace other energy forms such as solar water heaters (Verdeil, Arik et al. 2015).

Natural gas can only be represented as a transition fuel if storage technologies will develop sufficiently to maintain a stable grid with renewables (Steinke, Wolfrum et al. 2013) and/or if commercially viable Carbon Capture and Storage (CCS) technologies become available (Eide, de Sisternes et al. 2014). Natural gas is also thought to mediate new institutional arrangements and 'market design' to manage such transition (Haller, Ludig et al. 2012). The risks are that temporary solutions become permanent and natural gas becomes entrenched in contemporary infrastructures and economies. Furthermore, the reliance on gas hinders a deeper social change towards low carbon societies. Ultimately, natural gas power plants cannot achieve carbon reductions without additional technological fixes such as carbon capture and storage, which currently are not commercially viable (Zhang, Myhrvold et al. 2014).

In the likely context of global abundance of natural gas, natural gas should not be included as part of 'mitigation policies' (McJeon, Edmonds et al. 2014). Talking of natural gas as a 
transition fuel may legitimise its extraction in contexts were it is not substituting more polluting fuels, and hence, it does not play a role in mitigation (Stephenson, Doukas et al. 2012). Finally, the substitution of coal by natural gas in a country does not necessarily mean that this coal is kept in the ground. Instead, the reduction of the price of coal due to its competition with gas may lead to its use elsewhere in the energy chain. For example, the availability of cheaper coal may induce a rebound effect leading to greater consumption of coal in SMEs or households (Abrahams, Samaras et al. 2015). Internationally, emissions may simply be displaced. For example, the abundance of natural gas in the US has led to exports towards East Asia, where coal is currently used (Bohnengel, Patino-Echeverri et al. 2014).In conclusion, there are little grounds to use climate finance to support gas-fuelled electricity generation.

\section{Energy access in the household}

At the household level natural gas emerges as an accessible fuel, easily divided in smaller units that can be accessed by poor people. Global estimations suggest that residential energy use is still largely dependent on biomass, with about $40 \%$ of the total energy coming from that sector (Nejat, Jomehzadeh et al. 2015). While the percentage of population dependent on biomass decreased from $62 \%$ to $41 \%$ between 1980 and 2010 , the total population depending on these fuels remained stable around 2.8 billion during the three decades (Bonjour, Adair-Rohani et al. 2015). The use of solid fuels is particularly prevalent in Africa and South East Asia.

Liquefied Petroleum Gas (LPG), distributed in canisters as propane or butane, is widely used for cooking, and constitutes an alternative for biomass-dependent households. The substitution of biomass by LPG is thought to have five different benefits (Smith, Rogers et al. 2005):

1) Reduce indoor pollution, accidents and improve the health of household members;

2) Reduce GHG emissions associated with household cooking;

3) Reduce pressure on local forest resources;

4) Increase the availability of agricultural refuse for return to the soil;

5) Eliminate the time, work and risks dedicated to the collection of biomassparticularly suffered by women and children. 
Following this, fuel switching in households cannot be considered purely in terms of climate change mitigation objectives alone, but rather, the whole range of benefits provided by fuel switching has to be considered. LPG compares favourably with other cookstove fuels available to poor families. The comparison of emissions from cookstoves depends on fuel type, cook stove efficiency, whether biomass is sustainably harvested, cooking practices and similar contextual factors. When using advanced technology cookstoves, LPG emits on average half the emissions than biomass or charcoal for the same amount of cooking energy. LPG may also help to reduce the emission of pollutants such as black coal, which may have an immediate impact in reducing the greenhouse effect. This comparison, however, could be further developed with a Life Cycle Assessment of different biomass sources, including the impacts on forests and infrastructure needs.

Biomass-dependency is associated with poverty. Because women and children are often in charge of cooking, they may be particularly vulnerable to a fall in an energy-provision trap: they may need to spend precious working and studying time collecting fuels and watching the long process of cooking with biomass. A study in the North of India, for example, found that women and girls walk an average of 30 kilometres every morning, 2-3 hours, to collect the biomass needed for cooking (Parikh 2011). They may also be particularly vulnerable to the health impacts of indoor cooking. In India, for example, neonatal deaths clearly correlate with the use of high polluting fuels (coal, kerosene or biomass) instead of gas (Epstein, Bates et al. 2013). LPG may have a crucial impact in reducing poverty by reducing the need for collecting and cooking with biomass. The benefits of LPG have to be understood in context, as LPG may make families more dependent on external sources of income.

There needs to be an infrastructure to deliver and distribute LPG. Commonly LPG has higher penetration in urban as opposed to rural areas and among higher income households (Gangopadhyay, Ramaswami et al. 2005). In Indonesia, for example, an LPG programme has been able to deliver fuel switching at scale, bringing LPG to more than 50 million households, but benefiting mainly middle and higher income people (Andadari, Mulder et al. 2014). Morocco and Vietnam are other well-known examples of rapid adoption of LPG. Programmes such as these demonstrate the importance of an enabling environment, with an adequate regulatory framework for the delivery of LPG and an industry capable to supply 
LPG in a sustainable and economical manner. They also show that governments can have an important role in promoting the fuel switch, independently from the availability of ODA. However, people may not want to use LPG. Fuel adoption is a crucial issue here and is often misunderstood because of an emphasis on assuring affordability (Foell, Pachauri et al. 2011). Households, for example, do not change from one fuel to another; instead, they adapt their cooking practices to the resources available, including fuels but also cookstoves, family demands, house architecture, time available or food cultures. These patterns, however, are culturally dependent and often are not well understood. The potential of gas to facilitate energy access can only be explained in context as the case studies below demonstrate (see section 6).

\section{Using gas that would otherwise be flared or vented}

Flaring and venting are both common procedures to manage excess gas and have become a common practice in many oil and gas wells and refineries. This is a measure to maintain equipment in cases of over pressure, but in practice, it leads to the burning and release of GHG emissions from a fuel which could be used elsewhere. The World Bank has led a "Zero Routine Flaring by 2030" initiative, which was endorsed in April 2015 by several fossil fuel producing countries (including Angola, Republic of Congo, Cameroon and Gabon) and ten major oil companies. The objective is to reduce the release of waste gas with the implementation of state-of-the-art technologies to stop flaring.

Nigeria is, after Russia, the largest producer of flare gas in the world. Flaring safety practices which started in 1957 are routine today as companies find it more profitable to burn the gas than to reinject it or distribute it locally (Anejionu, Blackburn et al. 2014). Up to 47\% of the gas produced may be flared, despite a reduction on the levels of flaring and the realisation that this represents a loss of potential earnings (Anomohanran 2012). In addition to GHG emissions, flaring has detrimental environmental consequences locally. Gas flaring generates black carbon, a toxic aerosol which affects human health directly (Giwa, Adama et al. 2014). Gas flaring is linked to a decrease of yields in major crops such as cassava (Dung, Bombom et al. 2008).

Environmental impacts are compounded with the fact that flare gas is an activity which concentrates over hotspots during prolonged periods of times, sometimes spanning 
decades (Anejionu, Blackburn et al. 2014). The reuse of potentially-flared gas for power generation or for a pipeline has been planned by oil companies such as Shell and Total, but so far there is little evidence that these projects have been effective or have managed to bring a direct benefit to local populations.

The example of Nigeria suggests that gas flaring and venting is a practice which is, in its majority, avoidable. While in countries such as the US, Saudi Arabia, China and Canada the share of flare gas is smaller than their share of oil production, in countries like Nigeria, the share of flared gas is much higher than their share of oil production. Key factors in determining the levels of emissions are the remoteness of locations and the lack of regulatory and enforcement frameworks to control waste gas. While a certain level of vented and flared gas may be unavoidable, the largest proportion of waste gas corresponds to industries not meeting their duty of care in countries such as Nigeria, where the government may lack the will and enforcement capacity to ensure oil exploitation is done with the least possible environmental impact.

Questions remain over the extent to which waste gas recovery projects are truly within the remit of the ICF. An ODA subsidy is not appropriate for activities that fall from within the duty of care of oil companies. Moreover, carbon market mechanisms, such as the Joint Implementation mechanism that mirrors the CDM operation in developed countries, have created perverse incentives that lead to increase the production of waste gases as a means to increase credit revenues from waste gas abatement in countries such as Ukraine and Russia (Schneider and Kollmuss 2015).

For the ICF to fund waste gas recovery projects there should be an explicit justification of how the project meets the requirement of poverty alleviation. The first beneficiary of gas recovery projects is the oil industry, but that does not translate into direct benefits to communities. Actions deriving from a sense of corporate social responsibility are generally unable to reach communities sustainably. In the CDM database there is a methodology (AM0077) which addresses explicitly the recovery of gas for specific user groups. However, there has never been any registered project in the database which has used that methodology. Thus, there is significant scope for the ICF to fund demonstration projects in which gas, which would otherwise be flared or vented, is recovered to provide energy 
access directly to low income communities, particularly through the development of off-grid applications and the development of new community-based business models.

\section{Case studies of gas-related projects}

The following case studies represent extreme cases of natural gas-related projects. The cases include an LPG fuel switch project targeting low income communities in Sudan; a nation-wide fuel switching programme in Indonesia; and a waste gas recovery project in Nigeria.

\subsection{The Low Smoke Stoves Project in Sudan}

The objective of the Low Smoke Stoves Project in Sudan was to distribute LPG canisters and cookstoves to 10,000 households. The project operated in El Fasher, the capital of North Darfur where LPG penetration is around $10 \%$. In its initial phase, of three years, the project reached 3,600 households.

The project was initiated by Carbon Clear following a pilot project funded by DFID. Carbon clear found the means to fund the project with voluntary carbon credits. Together with Carbon Clear, the project is implemented on the ground by the Women's Association Development Network (WDAN) who have a number of functions, including: building a network of families, managing membership registrations, training households in the use of the cookstoves, and monitoring their use. The NGO Practical Action provides support and coordination. Nile Petroleum delivers the gas cylinders, normally $12.5 \mathrm{~kg}$ cylinders, and accessories. The project has also led to the introduction of smaller cylinders of $6 \mathrm{~kg}$ and $4 \mathrm{~kg}$, which can be transported easily to more remote areas.

Maintaining an LPG stove is much cheaper than maintaining one on charcoal or firewood, particularly in a country like Sudan in which charcoal and firewood are expensive commodities because of the growing scarcity of biomass fuels. Carbon Clear, for example, explains that the cost of refilling a $12.5 \mathrm{~kg}$ LP Gas cylinder are $10 \$ \mathrm{USD}$, while a $70 \mathrm{~kg}$ sack of charcoal costs 22-30 US\$. The reduced costs of cooking can translate directly into disposable incomes. Women are particularly benefited by simply having more time for their lives. Finally, households benefit from a direct health improvement resulting from reducing indoor air pollution. Biomass solid fuels such as wood, crop residues, and dung release large amounts of particulates, carbon monoxide and other pollutants which provoke a whole 
range of respiratory, skin and eye health problems. Switching to LPG reduces most pollutants by $95 \%$, while also reducing energy consumption.

Reductions of greenhouse gas emissions are linked to the switch to a more efficient and cleaner burning fuel in low income communities. The project team estimates that the delivery of 10,000 LPG cook stoves in El Fasher will help save over 400,000 tonnes of carbon monoxide over the lifetime of the project. The energy consumption of these communities is so low that the impact on global emissions may be of little significance. Yet, in addition to reducing emissions directly, the use of LPG reduces the pressure on local forest resources, which in an area suffering from desertification may be of great significance. For that reason, the Low Smoke Stoves project in Sudan has received 'Verified Emission Reduction' (VER) credits, which are available to business who want to voluntarily offset their carbon emissions. These credits have also been awarded the Gold Standard, which recognises both the real and verifiable carbon emissions and a measurable contribution to sustainable development worldwide.

Carbon Clear stresses that this scheme is cost-effective, as it is based on a microfinance system which funds itself. The project team provides loans for families to afford an LPG stove and a canister. The initial costs of the equipment are about US\$160. The microfinance loan enables fronting the initial costs, but these costs are repaid in 8-10 months by women who save income by switching to LPG. So far, repayment rates in the programme have been in excess of $90 \%$. In this way the project also demonstrates the financial mechanisms that can connect voluntary carbon credits to direct benefits for deprived communities.

This model appears to be sustainable and transformational. The team is now rolling over a second phase in which they plan to introduce additional 15,000 stoves. Project leaders are proud of these achievements, but in particular, they highlight how LPG has deeply changed the lives of women. Spill over effects may facilitate the penetration of LPG in El Fasher.

\subsection{Indonesia's Government Kerosene to LPG Fuel Switch}

From 2007 to 2011 the government of Indonesia implemented a programme to switch 50 million households from kerosene to LPG (Budya and Yasir Arofat 2011). The programme included several strands of simultaneous intervention to facilitate the switch, to create an enabling infrastructure and regulatory environment; developing the LPG industry; and 
developing consumer awareness. Key aspects of the switch were a survey of consumer preferences; the support of the LPG industry to supply the programme; and investment in distribution infrastructure. Creating awareness of the switch was an important component of the programme and participating households received a free "Initial Package", consisting of a $3 \mathrm{~kg}$ LP Gas cylinder, a first gas-fill, and a one-burner stove, hose, and regulator.

The LPG programme benefited mostly medium and higher income households in suburban areas (Andadari, Mulder et al. 2014). An evaluation of the extent to which the programme reduced energy poverty, however, found that while the programme caused a large shift from kerosene to LPG, the programme did not substantially reduce energy poverty, although it alleviated extreme cases of energy poverty (Ibid). However, the programme had other benefits such as the establishment of new industrial facilities to process LPG and the creation of LPG-related jobs (which Pertamina, the national oil company, has estimated in 38,000 new jobs) (Budya and Yasir Arofat 2011).

LPG substituted kerosene. Pertamina estimates that the reduction of 6 million kilolitres of kerosene per year translates into a reduction of 8.4 million tonnes of $\mathrm{CO} 2$ eq per year. In addition, the fuel switch also reduces the emissions associated with kerosene.

One of the key successes of the programme has been its financing. The switch was initially motivated by the high costs of kerosene subsidies paid by the government of Indonesia (which in 2006 accounted for $57 \%$ of the state's total petroleum product subsidy). By 2012, the fuel switch had saved the Indonesian state US\$6.9 billion. The programme also reduced the country's dependence of kerosene and supported the development of the LPG industry. The scale and speed of the project has been impressive.

There have been some hurdles related to the complexity of the distribution network needed to undertake such a project, the rise in prices of both kerosene and LPG and the incidence of LPG accidents, which, while being rare, have compromised the reputation of the programme. Yet, the programme shows the potential to reach scale through fuel substitution with the government backing in a country like Indonesia.

\subsection{The SUNGAS project, Nigeria}

The SUNGAS project is an EU-funded project led by an international consortium led by the International Institute of Environment and Development whose goal is to reduce poverty 
and support socio-economic development in the Niger Delta by promoting decentralised access to sustainable modern energy services (Wilson 2008). In a country like Nigeria with abundant fossil fuel resources, $60 \%$ of the people lacks access to electricity. This problem is particularly acute in rural and remote areas such as those in the Niger Delta. Efforts to increase electric power generation and reduce gas flaring, such as the Nigerian National Integrated Power Project (NIPP), have yet not reached communities on a large scale (for a review see: Eleri, Ugwu et al. 2012).

There is an increasing interest in the potential for off-grid, community-managed projects to address the challenges of energy access locally. For example, oil companies attempt to benefit communities directly through the establishment of local generation facilities. However, developing community-based projects is not straightforward. From ensuring adequate monitoring and maintenance, to developing appropriate business models for the sustainable provision of energy in the long-term, maintaining off-grid projects requires a great deal of experimentation on the ground which can only be delivered in cooperation with local partners (Isoun 2014).

The SUNGAS Project focused on the question about how to make it possible to give access to modern energy services to all communities. They follow a three-legged strategy based on advocacy, demonstration and research. They have influenced the development of a policy framework and have worked in community demonstration projects, one of which aims to demonstrate the involvement of communities on gas-flare capture projects. They have also constituted an Energy Policy Forum and Community Energy Council to work towards the project's goal beyond its lifetime.

The SUNGAS Project has not had a large impact on poverty reduction yet. However, when talking about new technologies and new business models for service provision, the objective is to create the policy and investment climate in which alternatives can be generated. What the SUNGAS Project exemplifies is the difficulties to reach the poor, even when projects are implemented locally. In the Niger Delta, for example, NGOs play a key role in managing and delivering projects where the strained capacity of the government does not reach and monitoring extractive activities. However, as the SUNGAS Project showed, NGOs' capacity has been constrained by current systems of funding and the burdens put on them by 
donors. Hence, ensuring local capacity and finance for community-energy projects should be the priority for poverty reduction.

The CDM experience suggests that projects directed towards the recovery of gas in oil fuels may have an important impact on emissions reductions. However, there is little evidence of the potential emission reductions of gas flare capture projects which intend to benefit communities directly, such as in the SUNGAS project. The SUNGAS project has to be evaluated because of its capacity to find out alternative routes for action (its transformative potential), rather than because of its actual emission reductions.

\section{Discussion}

Table 1 below provides an overview of how the different case studies would have met possible criteria that may be used in the ICF. A few analytical conclusions may be extracted from reading the table:

1. Gas-related projects are complex interventions that require context-specific knowledge of both the effects of technology and the possible business models that can work in context;

2. Energy access projects need to be understood as providing a whole range of sustainable benefits, from improving local health to reducing emissions;

3. The reduction of emissions is not a given and depends on specific baseline conditions;

4. There are innovative business and financial models that may enable the financing of many of these projects without ODA;

5. Transformational effects have to be understood in relation to broader cultures of energy delivery and use.

[Table 1- Near here]

There are questions about the extent to which these projects could have been funded with the ICF. In Low Smoke Stoves Project in Sudan, the reduction of emissions are significant not in terms of actual reductions (which will be small because consumption is small) but in terms of preventing further deforestation. The LPG programme in Indonesia is a clear success in terms of delivery and implementation. However, the main justification for the project was saving funds from kerosene subsidies. This suggests that similar projects should 
self-financed without ODA assistance because they are economically viable. Similar requirements apply in the case of reducing flare gas projects in Nigeria. The onus of the reduction of gas flaring should be on the companies, and they should not receive additional subsidies to fund them. A subsidy makes sense only in cases such as the SUNGAS project, in which the purpose is to demonstrate how gas flaring projects can benefit communities directly. Thus, waste gas recovery projects have to be accompanied by an appropriate justification for the development of associated off-grid projects which emphasise energy access and new business models that enable communities to own the project. A key insight of the SUNGAS and the Low Smoke Cookstoves Project is that energy is a sensitive issue that requires understanding local cultures at a deeper level that may only be accessible to a local partner. Supporting local partners can enable the development of innovative business models and lead to transformative change, but they involve considerable risk.

Table 2 presents a similar analysis, this time to evaluate different types of projects related to natural gas. Large investment projects to fund infrastructure for natural gas exploration, transportation, electricity generation or transmission are likely to be outside the remit of the ICF. There may be exceptions, for example, in cases in which the ICF funds technical assistance or regulatory projects to develop national, regional or city-based strategies in which natural gas may play a part.

[Table 2- near here]

Household-oriented programmes for energy access, such as programmes to switch from biomass or kerosene to LPG, have multiple environmental, social and economic benefits. This type of programme will have a multi-dimensional impact on poverty alleviation not only reducing the costs of energy services, but also increasing the time available for women and girls, reducing their insecurity and improving the household health. The actual impact of emission reductions will depend on a number of contextual factors, but LPG could provide a sound case for ICF investments when no other means of financing are available.

In the case of waste gas that would otherwise be vented or flared, there may be scope for ICF investment provided that certain caveats are addressed in the project, including, 1) not subsidising activities that would otherwise be funded by the oil industry as they constitute best practice in oil exploration; and 2) demonstrating the poverty alleviation benefits through community involvement or off-grid energy programmes. 



\section{Conclusion}

This paper argues that, generally, gas-related projects are not within the remit of the ICF, and should rarely be considered for climate finance. However, the paper also suggests that a blanket ban on gas-related projects is not appropriate, because such a ban would prevent mechanisms such as the ICF from funding some exceptional cases in which funding a gasrelated project may justifiable. The overall message is that the ICF has to help making a decisive move away from fossil fuels and this will not be consistent with continuing funding gas-related projects in instances other than these exceptions mentioned here. It is important to dispel the image of natural gas as a somewhat cleaner fuel, because such an image can only be constructed in relation to the tremendous impacts of coal. On its own, natural gas is another fossil fuel, and new natural gas-related infrastructures represent a renewed commitment to carbon emissions. 


\section{REFERENCES}

Abrahams, L. S., C. Samaras, W. M. Griffin and H. S. Matthews (2015). "Life Cycle Greenhouse Gas Emissions From US Liquefied Natural Gas Exports: Implications for End Uses." Environmental Science \& Technology 49(5): 3237-3245.

Andadari, R. K., P. Mulder and P. Rietveld (2014). "Energy poverty reduction by fuel switching. Impact evaluation of the LPG conversion program in Indonesia." Energy Policy 66: 436-449. Anejionu, O. C. D., G. A. Blackburn and J. D. Whyatt (2014). "Satellite survey of gas flares: development and application of a Landsat-based technique in the Niger Delta." International Journal of Remote Sensing 35(5): 1900-1925.

Anomohanran, O. (2012). "Determination of greenhouse gas emission resulting from gas flaring activities in Nigeria." Energy Policy 45: 666-670.

Bohnengel, B., D. Patino-Echeverri and J. Bergerson (2014). "Environmental Implications of United States Coal Exports: A Comparative Life Cycle Assessment of Future Power System Scenarios." Environmental Science \& Technology 48(16): 9908-9916.

Bonjour, S., H. Adair-Rohani, J. Wolf, N. G. Bruce, S. Mehta, A. Prüss-Ustün, M. Lahiff, E. A. Rehfuess, V. Mishra and K. R. Smith (2015). "Solid fuel use for household cooking: country and regional estimates for 1980-2010."

Brandt, A. R., G. A. Heath, E. A. Kort, F. O'Sullivan, G. Pétron, S. M. Jordaan, P. Tans, J. Wilcox, A. M. Gopstein, D. Arent, S. Wofsy, N. J. Brown, R. Bradley, G. D. Stucky, D. Eardley and R. Harriss (2014). "Methane Leaks from North American Natural Gas Systems." Science 343(6172): 733-735.

Budya, H. and M. Yasir Arofat (2011). "Providing cleaner energy access in Indonesia through the megaproject of kerosene conversion to LPG." Energy Policy 39(12): 7575-7586.

Busch, C. and E. Gimon (2014). "Natural Gas versus Coal: Is Natural Gas Better for the Climate?" The Electricity Journal 27(7): 97-111.

Davis, S. J., K. Caldeira and H. D. Matthews (2010). "Future CO2 Emissions and Climate Change from Existing Energy Infrastructure." Science 329(5997): 1330-1333.

Davis, S. J. and R. H. Socolow (2014). "Commitment accounting of $\mathrm{CO} 2$ emissions." Environmental Research Letters $9(8)$.

Dung, E. J., L. S. Bombom and T. D. Agusomu (2008). "The effects of gas flaring on crops in the Niger Delta, Nigeria." GeoJournal 73(4): 297-305.

Eide, J., F. J. de Sisternes, H. J. Herzog and M. D. Webster (2014). "CO2 emission standards and investment in carbon capture." Energy Economics 45: 53-65.

Eleri, E. O., O. Ugwu and P. Onuvae (2012). Low-carbon energy development in Nigeria. London, International Institute for Environment and Development.

EPA (2000). Greenhouse gases from small-scale combustion devices in developing countries: phase IIA (Household Stoves in India)- EPA/600/R-00/052, Environmental Protection Agency.

Epstein, M. B., M. N. Bates, N. K. Arora, K. Balakrishnan, D. W. Jack and K. R. Smith (2013).

"Household fuels, low birth weight, and neonatal death in India: The separate impacts of biomass, kerosene, and coal." International Journal of Hygiene and Environmental Health 216(5): 523-532.

Foell, W., S. Pachauri, D. Spreng and H. Zerriffi (2011). "Household cooking fuels and technologies in developing economies." Energy Policy 39(12): 7487-7496.

Gangopadhyay, S., B. Ramaswami and W. Wadhwa (2005). "Reducing subsidies on household fuels in India: how will it affect the poor?" Energy Policy 33(18): 2326-2336.

Giwa, S. O., O. O. Adama and O. O. Akinyemi (2014). "Baseline black carbon emissions for gas flaring in the Niger Delta region of Nigeria." Journal of Natural Gas Science and Engineering 20: 373-379. Goldenberg, S. (2015). UN green climate fund can be spent on coal-fired power generation. The Guardian

Haller, M., S. Ludig and N. Bauer (2012). "Decarbonization scenarios for the EU and MENA power system: Considering spatial distribution and short term dynamics of renewable generation." Energy Policy 47(0): 282-290. 
Hayhoe, K., H. Kheshgi, A. Jain and D. Wuebbles (2002). "Substitution of Natural Gas for Coal:

Climatic Effects of Utility Sector Emissions." Climatic Change 54(1-2): 107-139.

IDFC (2014). Green Finance Mapping for 2013, IDFC.

IGU (2015). Natural Gas, A Partner for Renewable Energy- Report to the G20 Energy and

Sustainability Working Group, International Gas Union.

Isoun, M. (2014). Staying power. Can communities sustain solar-powered water projects in the Niger Delta? London, International Institute for Environment and Development.

Lafrancois, B. A. (2012). "A lot left over: Reducing CO2 emissions in the United States' electric power sector through the use of natural gas." Energy Policy 50: 428-435.

Larson, E. D., Z. Li and R. H. Williams (2012). Chapter 12 - Fossil Energy. Global Energy Assessment Toward a Sustainable Future. Cambridge University Press, Cambridge, UK and New York, NY, USA and the International Institute for Applied Systems Analysis, Laxenburg, Austria: 901-992.

Lechtenboehmer, S., C. Dienst, M. Fischedick, T. Hanke, R. Fernandez, D. Robinson, R. Kantamaneni and B. Gillis (2007). "Tapping the leakages: Methane losses, mitigation options and policy issues for Russian long distance gas transmission pipelines." International Journal of Greenhouse Gas Control 1(4): 387-395.

Levi, M. (2013). "Climate consequences of natural gas as a bridge fuel." Climatic Change 118(3-4): 609-623.

Liang, F.-Y., M. Ryvak, S. Sayeed and N. Zhao (2012). "The role of natural gas as a primary fuel in the near future, including comparisons of acquisition, transmission and waste handling costs of as with competitive alternatives." Chemistry Central Journal 6.

Makholm, J. D. (2015). "Regulation of Natural Gas in the United States, Canada, and Europe: Prospects for a Low Carbon Fuel." Review of Environmental Economics and Policy 9(1): 107-127. McJeon, H., J. Edmonds, N. Bauer, L. Clarke, B. Fisher, B. P. Flannery, J. Hilaire, V. Krey, G. Marangoni, R. Mi, K. Riahi, H. Rogner and M. Tavoni (2014). "Limited impact on decadal-scale climate change from increased use of natural gas." Nature 514(7523): 482-485.

Nejat, P., F. Jomehzadeh, M. M. Taheri, M. Gohari and M. Z. Abd. Majid (2015). "A global review of energy consumption, $\mathrm{CO} 2$ emissions and policy in the residential sector (with an overview of the top ten $\mathrm{CO} 2$ emitting countries)." Renewable \& Sustainable Energy Reviews 43: 843-862.

NYT (2015). Norway Divests From Coal. The New York Times.

Parikh, J. (2011). "Hardships and health impacts on women due to traditional cooking fuels: A case study of Himachal Pradesh, India." Energy Policy 39(12): 7587-7594.

Schneider, L. and A. Kollmuss (2015). "Perverse effects of carbon markets on HFC-23 and SF6 abatement projects in Russia." Nature Clim. Change advance online publication.

Schumacher, K. and R. D. Sands (2006). "Innovative energy technologies and climate policy in Germany." Energy Policy 34(18): 3929-3941.

Shearer, C., J. Bistline, M. Inman and S. J. Davis (2014). "The effect of natural gas supply on US renewable energy and $\mathrm{CO} 2$ emissions." Environmental Research Letters 9(9).

Smith, K. R., J. Rogers, S. C. Cowlin and W. L. Association (2005). Household fuels and ill-health in developing countries: what improvements can be brought by LP gas?, World LP Gas Association. Stanek, W. and R. Bialecki (2014). "Can natural gas warm the climate more than coal?" Fuel 136: 341-348.

Steinke, F., P. Wolfrum and C. Hoffmann (2013). "Grid vs. storage in a 100\% renewable Europe." Renewable Energy 50(0): 826-832.

Stephenson, E., A. Doukas and K. Shaw (2012). "'Greenwashing gas: Might a 'transition fuel' label legitimize carbon-intensive natural gas development?"." Energy Policy 46: 452-459.

Trembath, A., M. Luke, M. Shellenberger and T. Nordhaus (2013). "Coal Killer: How Natural Gas Fuels the Clean Energy Revolution." Oakland: Breakthrough Institute.(http://thebreakthrough. org/images/main image/Breakthrough Institute Coal Killer. pdf).

Verdeil, E., E. Arik, H. Bolzon and J. Markoum (2015). "Governing the transition to natural gas in Mediteranean Metropolis: The case of Cairo, Istanbul and Sfax (Tunisia)." Energy Policy 78: 235-245. 
Wigley, T. L. (2011). "Coal to gas: the influence of methane leakage." Climatic Change 108(3): 601608.

Wilson, E. (2008). Sustainable utilisation of Nigeria's gas and renewable energy resources - project summary. London, International Institute for Environment and Development.

Yeo, S. (2015). Analysis: How much does the UK spend abroad on 'climate finance'? Carbon Brief. Zhang, X., N. P. Myhrvold and K. Caldeira (2014). "Key factors for assessing climate benefits of natural gas versus coal electricity generation." Environmental Research Letters 9(11): 114022. 